\title{
Taking cervical smears in departments of genitourinary medicine
}

\author{
MALCOLM GRIFFITHS, ${ }^{*} \dagger$ DAVID SANDERSON, ${ }^{*}$ LEONIE PENNA* \\ From the *Department of Genitourinary Medicine, Lloyd Clinic, Guy's Hospital, and the $\dagger$ Department of \\ Virology, United Medical \& Dental School, Guy's Campus, London
}

SUMMARY The smear taking practices of departments of genitourinary medicine were investigated by telephone inquiry. Departments seem to be broadly and equally divided into those where the smear is taken before the cervix is wiped or endocervical specimens are taken for microbiology, and those where the smear is taken afterwards.

In the unit at Guy's Hospital we compared cervical smears taken in both of these sequences and concluded that, to diagnose more cases of premalignant cervical disease, smears should be taken before any other cervical samples.

At the conference of the British Society of Colposcopists and Cervical Pathologists, it was suggested that smears taken in departments of genitourinary medicine (GUM) were likely to be of the highest quality and therefore among the most reliable.

We thought that wiping the cervix with cotton wool to remove vaginal secretions to prevent contamination of endocervical microbiology samples might have an adverse effect on the diagnostic quality of cervical smears taken later in the examination. We were also aware that smears were taken after endocervical samples in several other departments, and that sequence is recommended by many authors in Hare's recent textbook.' Smears taken at colposcopy have, however, been shown to be less reliable if they are taken after the cervix has been wiped with acetic acid. ${ }^{2}$

We therefore decided to examine smear taking practices in other departments of GUM in London, and to compare the two main techniques in the unit at Guy's Hospital.

\section{Patients and methods}

We carried out a telephone survey of all departments of GUM in London. We questioned the senior nurse in charge of the women's clinic or her immediate junior, and recorded the answers on a standard form. Respondents to our survey were not informed of the reason for

Address for reprints: Dr M Griffiths, Lloyd Clinic, Guy's Hospital, St Thomas Street, London SE1 9RT

Accepted for publication 26 September 1988 our inquiry, and as far as possible questions were nondirectional.

To compare the two main smear taking practices in our department, we alternated the sequence in which smears were taken according to the week of the study, all patients for whom cervical cytology was indicated had smears taken according to the protocol for the week in which they attended. Women attending one week thus effectively acted as controls for those attending in the following or preceeding week. No attempt was made to match controls any further, as we assumed that women from whom smears might be taken in one week were comparable to those attending in the previous or following week. The cytology department of this hospital was not aware that this study was being carried out, and smears were therefore read blind. Differences between the two groups of women were examined by the $\chi^{2}$ test.

\section{Results}

Table 1 shows the results of our telephone survey. Replies were obtained from 19 of the departments of GUM in London.

Table 1 Sequence of specimens taken in 19 departments of genitourinary medicine in London

\begin{tabular}{ll}
\hline Order of samples & No of clinics \\
\hline Cervical wipe-Microbiology-Cytology & 9 \\
Cervical wipe-Cytology-Microbiology & 2 \\
Cytology-Cervical wipe-Microbiology & 5 \\
Cytology-Microbiology-No wipe & 3 \\
\hline
\end{tabular}


Table 2 Results of cervical smears taken before, compared with after, wiping the cervix and taking endocervical samples (figures are numbers (percentages))

\begin{tabular}{|c|c|c|c|}
\hline Smear results & $\begin{array}{l}\text { Before } \\
(n=67)\end{array}$ & $\begin{array}{l}\text { After } \\
(n=61)\end{array}$ & $p$ \\
\hline $\begin{array}{l}\text { Normal or negative } \\
\text { Inadequate or unsatisfactory } \\
\text { Inflammatory } \\
\text { Mild or borderline atypia } \\
\text { Dyskaryosis } \\
\text { Wart virus infection } \\
\text { without dyskaryosis } \\
\text { All atypia, wart virus } \\
\text { infection, and dyskaryosis }\end{array}$ & $\begin{array}{l}22(33) \\
2(3) \\
12(18) \\
11(16) \\
6(9) \\
14(21) \\
31(46)\end{array}$ & $\begin{array}{c}33(54) \\
5(8) \\
9(15) \\
4(7) \\
2(3) \\
8(13)\end{array}$ & $\begin{array}{l}=0.05 \\
=0.02 \\
\text { NS } \\
<0.01 \\
<0.01 \\
=0.1 \\
<0.01\end{array}$ \\
\hline
\end{tabular}

Table 2 compares the results of cervical smears taken before with those taken after endocervical samples. Although there was an almost threefold difference between the numbers of inadequate or unsatisfactory smears from the two groups of women, this is not very important in clinical practice as the proportion of inadequate smears is small and all women having such a result could of course be recalled for a repeat smear. More important was the fact that significantly $(p<0.01)$ fewer cervical smears taken after the cervix had been wiped and endocervical specimens taken for microbiology showed dyskaryosis and atypia. This finding suggests that taking cervical smears after the other cervical specimens may lead to more false negative results and therefore failure to diagnose cervical intraepithelial neoplasia in some patients, who will thus be falsely reassured by negative smear results.

\section{Discussion}

The sequence in which cervical smears are taken obviously varies between departments of GUM in London. An overview of the results suggests that an important factor may be the unit where the consultant in charge of a department originally trained in the specialty. No objective evidence seems to have been produced in favour of a "microbiology first" protocol.

The results of our study comparing the two protocols suggests that to get the best yield from our cervical smears for cytology - in terms of diagnoses of premalignant cervical disease-we should take the smear before taking all other cervical samples and certainly before wiping the cervix with cotton wool.

We should also bear in mind, however, that our primary aim has so far been to detect sexually transmitted diseases (STDs). If we were to adopt this "new" approach we might prejudice detection of STDs, though several departments of GUM apparently use this sequence without any obvious affect on their ability to diagnose and treat STDs.

Finally, if we regard cervical cancer and cervical intraepithelial neoplasia as STDs, ${ }^{34}$ we perhaps ought to give at least equal consideration to their diagnosis and prevention to that hitherto given to diagnosing gonorrhoea and chlamydial infection.

We thank Faith Gardner, our health adviser, who helped record and collate some of the data; Dr S J Tovey, consultant in charge, for his co-operation and encouragement; and the nursing staff of the 19 departments of GUM for their cooperation in answering our questions.

MG is supported by a grant from the special trustees of Guy's Medical School.

\section{References}

1 Hare MJ, ed. Genital tract infection in women. Edinburgh: Churchill Livingstone, 1988.

2 Griffiths M, Turner MJ, Partington CK, Soutter WP. Should smears taken in a colposcopy clinic be taken before or after application of acetic acid? Acta Cytol (Baltimore) (in press).

3 Anonymous. Genital warts, human papillomavirus and cervical cancer. [Editorial] Lancet 1985;ii:1045-6.

4 Anonymous. Human papillomaviruses and cervical cancer: a fresh look at the evidence. [Editorial] Lancet 1987;i:725-6. 